\title{
How to approach orthognathic surgery in patients who refuse blood transfusion
}

\author{
Sang Hwan Lee, Dong Gyu Kim, Ho Seong Shin \\ Department of Plastic and Reconstructive Surgery, Soonchunhyang University College of Medicine, Bucheon, Korea
}

Background Some patients who need surgery refuse a blood transfusion because of their religious beliefs or concerns about blood-borne infections. In recent years, bloodless surgery has been performed successfully in many procedures, and is therefore of increasing interest in orthognathic surgery.

Methods Ten Jehovah's Witnesses who visited our bloodless surgery center for orthognathic surgery participated in this study. To maintain hemoglobin $(\mathrm{Hb})$ levels above $10 \mathrm{~g} / \mathrm{dL}$ before surgery, recombinant erythropoietin ( $r E P O)$ was subcutaneously administered and iron supplements were intravenously administered. During surgery, acute normovolemic hemodilution (ANH) and induced hypotensive anesthesia were used. To elevate the $\mathrm{Hb}$ levels to $>10 \mathrm{~g} / \mathrm{dL}$ after surgery, a similar method to the preoperative approach was used.

Results The 10 patients comprised three men and seven women. Their average $\mathrm{Hb}$ level at the first visit was $11.1 \mathrm{~g} / \mathrm{dL}$. With treatment according to our protocol, the average preoperative $\mathrm{Hb}$ level rose to $12.01 \mathrm{~g} / \mathrm{dL}$, and the average $\mathrm{Hb}$ level on postoperative day 1 was $10.01 \mathrm{~g} / \mathrm{dL}$. No patients needed a blood transfusion, and all patients were discharged without any complications.

Conclusions This study presents a way to manage patients who refuse blood transfusions while undergoing orthognathic surgery. rEPO and iron supplementation were used to maintain $\mathrm{Hb}$ levels above $10 \mathrm{~g} / \mathrm{dL}$. During surgery, blood loss was minimized by a meticulous procedure and induced hypotensive anesthesia, and intravascular volume was maintained by ANH. Our practical approach to orthognathic surgery for Jehovah's Witnesses can be applied to the management of all patients who refuse blood transfusions.

Keywords Blood transfusion / Orthognathic surgery / Jehovah's Witnesses

\author{
Correspondence: Ho Seong Shin \\ Department of Plastic and \\ Reconstructive Surgery, \\ Soonchunhyang University Bucheon \\ Hospital, Soonchunhyang University \\ College of Medicine, 170 Jomaru-ro, \\ Wonmi-gu, Bucheon 14584, Korea \\ Tel: +82-32-621-6931 \\ Fax: +82-32-621-5018 \\ E-mail: psshin@schmc.ac.kr
}

This paper was supported by the Soonchunhyang University Research Fund (grant No. 20200020).

Received: March 25, 2020 • Revised: June 22, 2020 - Accepted: July 14, 2020 pISSN: 2234-6163 • elSSN: 2234-6171 • https://doi.org/10.5999/aps.2020.00493• Arch Plast Surg 2020;47:404-410

\section{INTRODUCTION}

In recent years, there has been a growing demand for bloodless surgery in many surgical fields, including general surgery, arthroplasty, and even oncologic surgery. In the past, blood transfusions were often necessary in these surgical procedures because of excessive bleeding. However, a major concern is posed by patients who need surgery, but-because of religious beliefs or concerns regarding the blood-borne transmission of pathogens (e.g., HIV) — refuse transfusions. Recent developments in medication, surgical techniques, and instrumentation have reduced both the risks of bleeding and the operation time. With these developments, bloodless surgery has been performed successfully in many procedures [1-3]. 
Orthognathic surgery is widely used to correct three-dimensional facial deformities, but there is a risk of excessive bleeding because of the complicated vascularity of the maxillofacial region [4]. Excessive blood loss can be potentially fatal and can necessitate a blood transfusion [5]. However, developments in medication, surgical techniques, and instrumentation have improved the outcomes and reduced the risks of bimaxillary surgery. Bloodless surgery has also been developed to the point that it can be used in orthognathic surgery.

Our bloodless surgery center has successfully performed many surgical procedures without transfusions, and we have applied this method to Jehovah's Witness patients, who never consent to blood transfusions because of their religious beliefs. This practical approach to orthognathic surgery in Jehovah's Witnesses can be applied to the management of all patients who refuse blood transfusion.

\section{METHODS}

The study involved 13 patients who visited our non-blood transfusion treatment center and underwent orthognathic surgery from January 1, 2013 to March 31, 2016. The possible need for transfusion due to massive bleeding loss after orthognathic surgery was explained to them. They all refused blood transfusion based on their beliefs as Jehovah's Witnesses. In cases where heavy blood loss is expected during surgery in patients who have not consented to receive a blood transfusion, the operation can be performed according to the guidelines established at our bloodless surgery center (Fig. 1).

Patients with heart or lung diseases were excluded based on a thorough medical history. For patients who were taking hemorrhagic drugs (nonsteroidal anti-inflammatory drugs, aspirin, anticoagulant, steroids, herbal medicine, etc.), it was checked whether the drugs could be discontinued for a certain period of time. If the drugs could not be discontinued, the patients were excluded. Of the 13 patients, 10 were enrolled in this study.

The ethics committee of Soonchunhyang University Bucheon Hospital (IRB No. 2020-05-042) approved the protocol of this study.

\section{Preparation before surgery}

Hemoglobin $(\mathrm{Hb})$ levels were checked when a person who requested orthognathic surgery without blood transfusion first visited our bloodless surgery center. To manage their $\mathrm{Hb}$ levels, subcutaneous administration of recombinant erythropoietin (rEPO; darbepoetin alfa, 4,000 U) and intravenous iron supplementation (Venoferrum; ferric hydroxide sucrose complex, 100 $\mathrm{mg}$ ) were used. Our goal before surgery was to ensure that the

\section{Fig. 1. Guidelines for patients who refused blood transfusion}

Patients received subcutaneous (SC) administration of recombinant erythropoietin (rEPO) $(4,000 \mathrm{U}$, darbepoetin) and intravenous (IV) administration of one dose of iron supplementation (Venoferrum; ferric hydroxide sucrose complex, $100 \mathrm{mg}$ ).

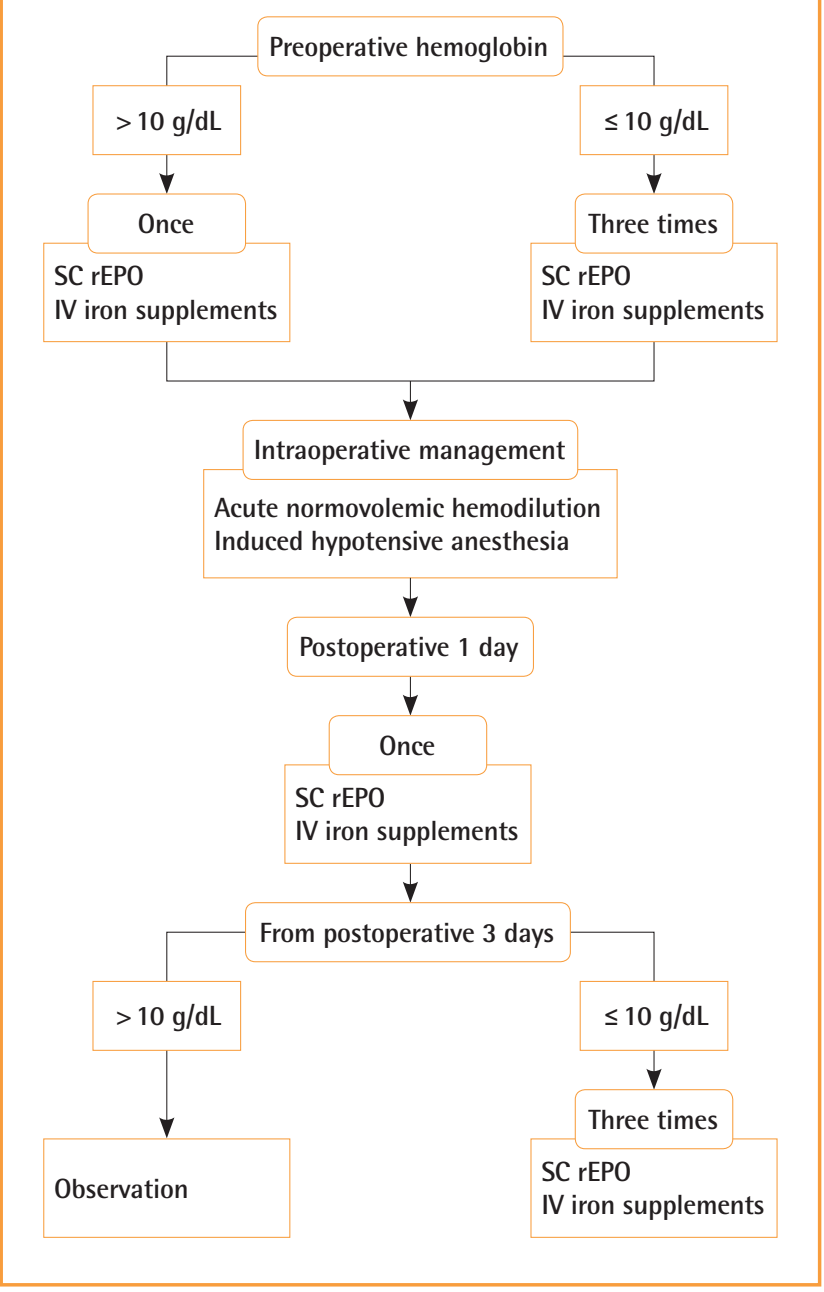

patient's $\mathrm{Hb}$ level was at least $10 \mathrm{~g} / \mathrm{dL}$ to withstand intraoperative and postoperative bleeding.

Therefore, we started different treatments depending on whether the patient's $\mathrm{Hb}$ exceeded $10 \mathrm{~g} / \mathrm{dL}$ (Fig. 1). If the $\mathrm{Hb}$ level exceeded $10 \mathrm{~g} / \mathrm{dL}, 4,000 \mathrm{U}$ of rEPO was administered subcutaneously and $100 \mathrm{mg}$ of iron supplementation was administered intravenously once prior to surgery. After 1 week, patients underwent surgery. If the $\mathrm{Hb}$ level was $\leq 10 \mathrm{~g} / \mathrm{dL}$ prior to surgery, repeated treatments were required to increase the $\mathrm{Hb}$ level to more than $10 \mathrm{~g} / \mathrm{dL}$. To do so, 4,000 $\mathrm{U}$ of rEPO was administered subcutaneously three times weekly, and $100 \mathrm{mg}$ of iron was administered intravenously daily. $\mathrm{Hb}$ levels were checked at 1-week intervals. When the Hb level exceeded $10 \mathrm{~g} /$ $\mathrm{dL}$, surgery was performed 1 week later. 


\section{Intraoperative management}

During surgery, acute normovolemic hemodilution (ANH) was used. At the start of surgery, the ratio of fluid to blood collected for hemodilution was planned to be between 1.5 and 2:1. After the patient was anesthetized, two units of blood $(600 \mathrm{~mL})$ was collected immediately, and 1,000 $\mathrm{mL}$ of crystalloid fluid was intravenously administered to maintain a systolic blood pressure above $90 \mathrm{mmHg}$. All collected blood was stored at room temperature and was infused to the patient after surgery. In all cases, the collected blood was kept within a closed circuit because of the religious beliefs of the patient.

Induced hypotensive anesthesia was also used in cooperation with an anesthesiologist. Vasodilators and blood pressure-lowering agents were administered by the anesthesiologist, but cardiac output was maintained even at low blood pressure. The anesthesiology team maintained a systolic blood pressure of 80-90 $\mathrm{mmHg}$ or a mean arterial pressure of $50-60 \mathrm{mmHg}$ in patients with normal blood pressure, in preparation for sudden hemorrhage or shock.

\section{Postoperative management}

Postoperative management can be divided into two major categories. First, it was necessary to compensate for the decrease in $\mathrm{Hb}$ caused by intraoperative bleeding, and second, it was necessary to stop the subsequent bleeding quickly. After orthognathic surgery, $\mathrm{Hb}$ levels tend to decrease because of extensive bleeding, so rEPO and iron were used starting the day after surgery to compensate for the decrease. Specifically, 4,000 U rEPO was administered subcutaneously and $100 \mathrm{mg}$ of iron supplementation was administered intravenously. The patient's $\mathrm{Hb}$ level was checked on postoperative day (POD) 1 and every 2 days thereafter until it reached $10 \mathrm{~g} / \mathrm{dL}$ or more (Fig. 1). If the $\mathrm{Hb}$ level was $\leq 10 \mathrm{~g} / \mathrm{dL}$ on POD $3, \mathrm{rEPO}$ and iron were administered. If the $\mathrm{Hb}$ level continued to be less than $10 \mathrm{~g} / \mathrm{dL}$, rEPO and iron were administered again. If the $\mathrm{Hb}$ level was $>10 \mathrm{~g} / \mathrm{dL}$ on POD 3 or 5 , observations were made without rEPO and iron. Furthermore, tranexamic acid was used to stop the bleeding. After surgery, 1,000 mg of tranexamic acid was administered intravenously. From POD 1 to POD 3, 1,000 to 2,000 mg of tranexamic acid was administered depending on the amount and color of the drainage. After POD 3, if there was no bleeding tendency, tranexamic acid was discontinued.

\section{Case}

A 21-year old female patient was hospitalized with a class III malocclusion (Fig. 2). Her preoperative $\mathrm{Hb}$ level was $11.9 \mathrm{~g} / \mathrm{dL}$ (hematocrit [Hct], 35.8 vol\%). The possible need for transfusion due to massive bleeding loss after two-jaw surgery was ex- plained to her. She strongly refused blood transfusion as a Jehovah's Witness. Starting a week before surgery, rEPO and iron supplementation were administered once as detailed above. The patient's $\mathrm{Hb}$ level immediately prior to surgery was $12.3 \mathrm{~g} /$ $\mathrm{dL}$ (Hct, $37.1 \mathrm{vol} \%$ ). The day prior to surgery, the patient signed a Medical and Liability Release Form, which freed the hospital of legal repercussions in the event of problems arising from the lack of blood transfusion. After general anesthesia was established, two units $(600 \mathrm{~mL})$ were extracted by ANH. At 3 hours postoperatively, the patient's $\mathrm{Hb}$ level was $9.4 \mathrm{~g} / \mathrm{dL}$. Bleeding at the surgical site was minimized using electrocautery and a meticulous surgical procedure. Five hours after surgery, the $\mathrm{Hb}$ level had dropped to $8.5 \mathrm{~g} / \mathrm{dL}$. The extracted blood was transfused within a closed circuit. The total blood loss during the operation was about $700 \mathrm{~mL}$. The morning after surgery, the patient's $\mathrm{Hb}$ level was $10.4 \mathrm{~g} / \mathrm{dL}$. The patient was cared for according to our hospital's postoperative protocol. She was stable, with no critical changes to vital signs including systolic blood pressure, and experienced no postoperative complications. On the day of discharge, the $\mathrm{Hb}$ level was $10.7 \mathrm{~g} / \mathrm{dL}$ (Hct, $32.2 \mathrm{vol} \%$ ).

\section{RESULTS}

Ten patients underwent orthognathic surgery without transfusion, of whom three were men and seven were women. Their mean age was 27.2 years (range, 21-32 years). They underwent the following surgical procedures: one patient received a LeFort I procedure, two patients underwent bilateral sagittal split ramus osteotomy, three patients underwent a two-jaw procedure, and four patients simultaneously underwent two-jaw and genioplasty procedures (Table 1 ).

Eight patients had $\mathrm{Hb}$ levels $>10 \mathrm{~g} / \mathrm{dL}$ (mean, $11.5 \mathrm{~g} / \mathrm{dL}$; range, $10.5-13.0 \mathrm{~g} / \mathrm{dL}$ ) when they visited our bloodless surgery center. They were treated with $\mathrm{rEPO}$ and iron supplementation once before surgery. After our protocol, their mean $\mathrm{Hb}$ level increased to $12.3 \mathrm{~g} / \mathrm{dL}$ (range, 11.5-13.5 g/dL) (Fig. 1). On the day after surgery, it decreased to $10.3 \mathrm{~g} / \mathrm{dL}$ (range, 9.5-11.5 g/ $\mathrm{dL})$. On the third day after surgery, it continued to decrease, reaching 9.5 g/dL (range, 8.2-10.8 g/dL). Six patients with $\mathrm{Hb}$ levels less than $10 \mathrm{~g} / \mathrm{dL}$ were treated again with $\mathrm{rEPO}$ and iron supplementation. Two patients with levels greater than $10 \mathrm{~g} / \mathrm{dL}$ were discharged. On the fifth day after surgery, their $\mathrm{Hb}$ level increased (Fig. 3). The mean $\mathrm{Hb}$ of the remaining six patients was $10.2 \mathrm{~g} / \mathrm{dL}$ (range, 9.2-10.5 g/dL).

Two patients had $\mathrm{Hb}$ levels $<10 \mathrm{~g} / \mathrm{dL}$ when they first visited our bloodless surgery center. Their $\mathrm{Hb}$ were 9.6 and $9.2 \mathrm{~g} / \mathrm{dL}$, respectively. They were treated with $\mathrm{rEPO}$ and iron supplementation once. After 1 week, their $\mathrm{Hb}$ levels were found to be 10.1 


\section{Fig. 2. Preoperative and 4-month postoperative findings}

A patient who underwent LeFort I osteotomy, BSSRO, and reduction genioplasty. (A) Preoperative photographic finding (anteroposterior view). (B) Preoperative photographic finding (lateral view). (C) Preoperative photographic finding (intraoral view). (D) Preoperative lateral cephalogram. (E) Postoperative photographic finding (anteroposterior view). (F) Postoperative photographic finding (lateral view). (G) Postoperative photographic finding (intraoral view). (H) Postoperative lateral cephalogram. BSSRO, bilateral sagittal split ramus osteotomy.
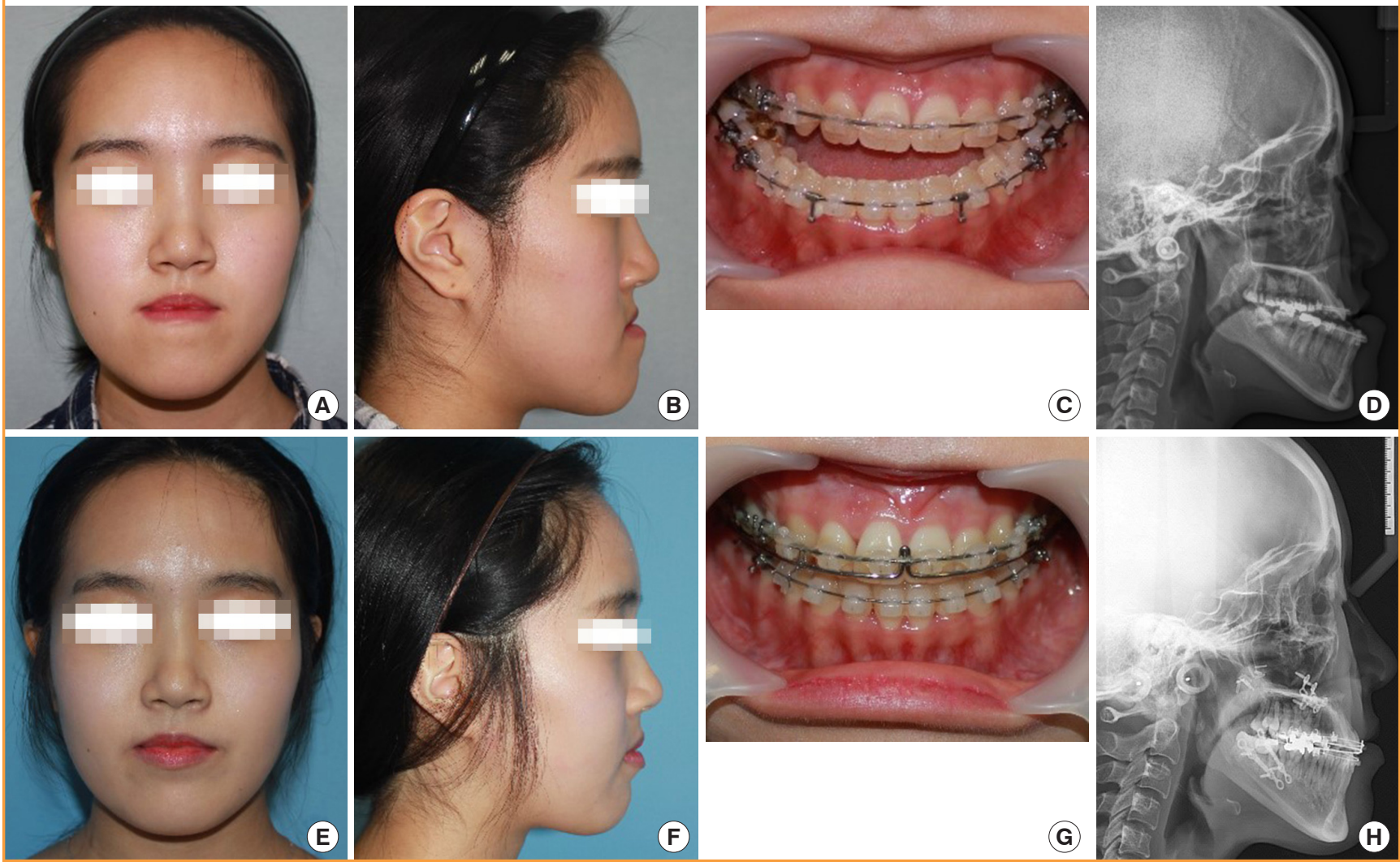

Fig. 3. Temporal patterns of hemoglobin levels

After implementing our preoperative protocol, the mean hemoglobin level increased to $12.3 \mathrm{~g} / \mathrm{dL}$. On the third day after surgery, the lowest levels were found. By fifth day after surgery, hemoglobin levels showed a tendency to increase. POD, postoperative day; BSSRO, bilateral sagittal split ramus osteotomy.

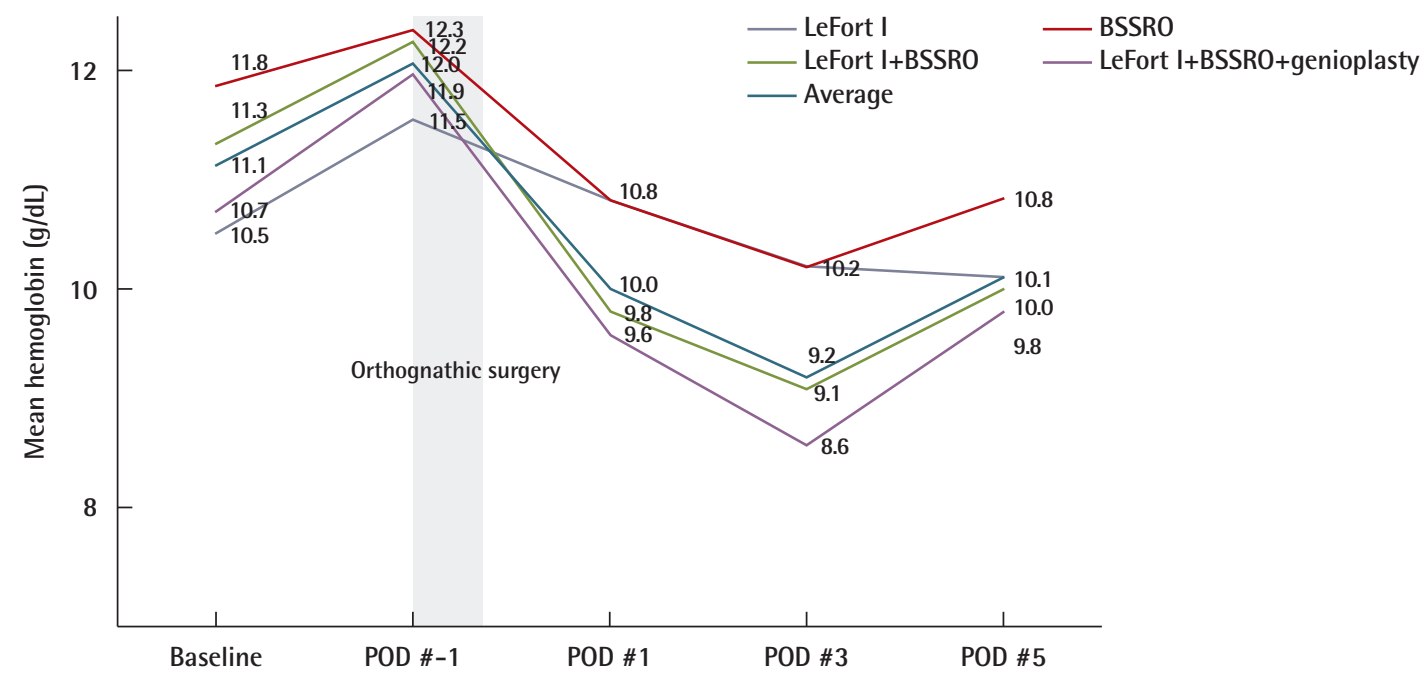


Table 1. Patient characteristics by operation, treatment method, and hemoglobin levels

\begin{tabular}{|c|c|c|c|c|c|c|c|c|c|c|c|}
\hline \multirow{2}{*}{$\begin{array}{c}\text { Patient } \\
\text { No. }\end{array}$} & \multirow{2}{*}{$\begin{array}{l}\text { Sex/ } \\
\text { age } \\
(y r)\end{array}$} & \multirow{2}{*}{ Operation } & \multirow{2}{*}{$\begin{array}{c}\text { Initial } \\
\mathrm{Hb} \\
\text { (g/dL) }\end{array}$} & \multicolumn{2}{|c|}{$\begin{array}{l}\text { Preoperative } \\
\text { preparation }\end{array}$} & \multirow{2}{*}{$\begin{array}{l}\text { Preoperative } \\
\text { Hb (g/dL) }\end{array}$} & \multirow{2}{*}{$\begin{array}{c}\text { POD } 1 \\
\mathrm{Hb} \\
(\mathrm{g} / \mathrm{dL})\end{array}$} & \multirow{2}{*}{$\begin{array}{c}\text { POD } 3 \\
\text { Hb } \\
(\mathrm{g} / \mathrm{dL})\end{array}$} & \multirow{2}{*}{$\begin{array}{c}\text { POD } 5 \\
\mathrm{Hb} \\
(\mathrm{g} / \mathrm{dL})\end{array}$} & \multirow{2}{*}{$\begin{array}{c}\text { POD } 7 \\
\mathrm{Hb} \\
(\mathrm{g} / \mathrm{dL})\end{array}$} & \multirow{2}{*}{$\begin{array}{c}\text { POD } 9 \\
\mathrm{Hb} \\
(\mathrm{g} / \mathrm{dL})\end{array}$} \\
\hline & & & & Iron (IV) & rEPO (SC) & & & & & & \\
\hline 1 & $M / 24$ & LeFort I & 10.5 & 1 & 1 & 11.5 & 10.8 & 10.2 & 10.1 & & \\
\hline 2 & $F / 32$ & BSSRO & 12.0 & 1 & 1 & 12.5 & 11.5 & 10.8 & 11.0 & & \\
\hline 3 & $M / 31$ & BSSRO & 11.5 & 1 & 1 & 12.1 & 10.1 & 9.5 & 10.5 & & \\
\hline 4 & $\mathrm{M} / 28$ & LeFort I+BSSRO & 13.0 & 1 & 1 & 13.5 & 10.5 & 9.5 & 10.5 & & \\
\hline 5 & $F / 31$ & LeFort I+BSSRO & 11.4 & 1 & 1 & 12.5 & 10.0 & 9.2 & 10.3 & & \\
\hline 6 & $F / 26$ & LeFort I+BSSRO & 9.6 & 7 & 3 & 10.5 & 9.0 & 8.5 & 9.2 & 9.6 & 10.1 \\
\hline 7 & $F / 21$ & LeFort I + BSSRO + sliding genioplasty & 11.9 & 1 & 1 & 12.3 & 10.4 & 9.2 & 10.2 & & \\
\hline 8 & $F / 26$ & LeFort I+ BSSRO + sliding genioplasty & 9.2 & 7 & 3 & 11.5 & 8.5 & 7.8 & 9.1 & 9.3 & 10.0 \\
\hline 9 & $F / 24$ & LeFort I+ BSSRO + sliding genioplasty & 10.5 & 1 & 1 & 11.7 & 9.5 & 8.2 & 9.2 & 9.5 & 10.1 \\
\hline 10 & $F / 29$ & LeFort I + BSSRO + sliding genioplasty & 11.2 & 1 & 1 & 12.0 & 9.8 & 9.0 & 10.5 & & \\
\hline
\end{tabular}

Hb, hemoglobin; IV, intravenous; rEPO, recombinant erythropoietin; SC, subcutaneous; POD, postoperative day; M, male; F, female; BSSRO, bilateral sagittal split ramus osteotomy.

and $10.2 \mathrm{~g} / \mathrm{dL}$, respectively (Table 1 ). Because their $\mathrm{Hb}$ levels were over $10 \mathrm{~g} / \mathrm{dL}$, after one more treatment with $\mathrm{rEPO}$ and iron supplementation, we planned surgery for 1 week after the last administration. Their preoperative $\mathrm{Hb}$ levels increased to 10.5 and $11.5 \mathrm{~g} / \mathrm{dL}$, respectively. Their Hb levels decreased until POD 3 and increased afterwards. However, their $\mathrm{Hb}$ levels remained under $10 \mathrm{~g} / \mathrm{dL}$ until POD 7 , and they therefore received rEPO and iron supplementation four times (immediately after surgery and on POD 3, 5, and 7). On POD 9, their $\mathrm{Hb}$ levels were $10 \mathrm{~g} / \mathrm{dL}$ or more and $\mathrm{rEPO}$ and iron were no longer administered.

Patients were discharged when their $\mathrm{Hb}$ level increased to 10 or more. Seven patients were discharged on POD 5 and two were discharged on POD 9. Transfusions were not required in any patients and complications were not observed.

\section{DISCUSSION}

Blood transfusions are the norm in cases of orthognathic surgery that involve massive bleeding. For the past 10 years, our hospital has successfully provided various bloodless surgical procedures to Jehovah's Witness patients and other patients who refuse blood transfusion. Our experiences have been positive.

Efforts have been made in the field of orthognathic surgery to measure, prevent, and predict blood loss. Pineiro-Aguilar et al. [6] conducted a systematic review of blood loss based on 17 studies, and the average intraoperative blood loss volume was $436.11 \pm 207.89 \mathrm{~mL}$. Blood loss requiring blood transfusion was observed in 13 patients. Ueki et al. [7] measured blood loss during orthognathic surgery in 62 patients, and reported that $216.6 \pm 143.3 \mathrm{~mL}$ of blood was lost in sagittal split ramus osteotomy procedures, while $343.6 \pm 179.9 \mathrm{~mL}$ of blood was lost when sagittal split ramus osteotomy was performed together with LeFort I osteotomy. In studies of factors affecting blood loss $[8,9]$, higher levels of blood loss were found in procedures with a longer operation time, bimaxillary surgery or LeFort I osteotomy, patients with a relatively low body mass index, and cases involving iliac bone grafting or genioplasty. In some cases [10], blood loss exceeded 2,000 $\mathrm{mL}$. The use of tranexamic acid to prevent blood loss in orthognathic surgery [11] and the use of thromboelastography to predict blood loss [12] are efforts to reduce complications from bleeding and to minimize the need for blood transfusion. Therefore, as in our study, preparing for intraoperative blood loss by checking preoperative $\mathrm{Hb}$ levels and augmenting $\mathrm{Hb}$ if necessary is an appropriate method for patients who refuse transfusion.

In this study, the temporal pattern of $\mathrm{Hb}$ was measured from before surgery to various postoperative time points, and the mean values are presented according to the type of surgery (Fig. 3). In all graphs, the lowest $\mathrm{Hb}$ level was shown on POD 3, with a decrease of $2.8 \mathrm{~g} / \mathrm{dL}$ compared to the preoperative $\mathrm{Hb}$ levels. Considering that healthy adults need to receive blood transfusions when their $\mathrm{Hb}$ level is lower than $7 \mathrm{~g} / \mathrm{dL}$, patient 8 would have been highly likely to need a transfusion if it had not been for the preoperative treatment because her $\mathrm{Hb}$ level was $7.8 \mathrm{~g} /$ $\mathrm{dL}$ on POD 3. Thus, checking postoperative $\mathrm{Hb}$ levels during follow-up and identifying trends in postoperative $\mathrm{Hb}$ increases can be an important factor in postoperative management.

Adherence to several aspects of the protocol is necessary. First, careful preoperative planning is crucial for successful outcomes. Prior to surgery, any risk factors that can exacerbate the patient's condition due to bleeding must be minimized. It must be determined whether the patient is taking medication that could increase bleeding risk during surgery; examples include aspirin, 
nonsteroidal anti-inflammatory drugs, anti-coagulants, and antiplatelet agents. When possible, these medications should be stopped. Moreover, to adequately prepare for expected bleeding, the $\mathrm{Hb}$ level should be adequately raised before surgery. Preparing a method that can compensate for post-surgical hemorrhage is critical. In general, to support hematopoiesis, folic acid, vitamin $B_{12}$, iron supplements, and/or rEPO can be applied. Shander and Javidroozi [13] reported that agents that promote hematopoiesis or hemostasis are acceptable to most Jehovah's Witnesses.

$\mathrm{Hb}$ levels can also be effectively raised prior to surgery using rEPO and iron supplements. By stimulating erythropoiesis, EPO can produce the equivalent of $1 \mathrm{U}$ of blood per week [1416]. Lin et al. [17] and Bacuzzi et al. [18] reported that iron significantly reduced the need for blood transfusion in combination with EPO. Using rEPO and iron, we successfully improved patients' $\mathrm{Hb}$ before orthognathic surgery. Patients' average $\mathrm{Hb}$ level increased from $11.1 \mathrm{~g} / \mathrm{dL}$ before surgery to $12.0 \mathrm{~g} / \mathrm{dL}$ after approximately 7 days (Fig. 3). However, EPO has the known side effects of headaches and increased blood pressure. Dixon and Smalley [19] and Ball and Winstead [20] reported that this medication should not be administered to patients with high blood pressure that cannot be treated or to patients who are hypersensitive to medications. Therefore, such patients require particular care regarding the use of EPO.

The second relevant aspect is the intraoperative technique. Loss of blood during surgery must be minimized. Induced hypotension anesthesia can reduce bleeding by lowering the hydrostatic pressure of damaged vessels. Meticulous surgical technique is required to decrease intraoperative blood loss. This includes incorporating careful hemostasis methods, including using electrocautery, argon beam-enhanced dissectors, and ultrasonic coagulator dissectors (harmonic scalpels). Administering an appropriate anti-hemorrhagic agent can also be helpful for minimizing hemorrhage. Vitamin $\mathrm{K}$ as a coagulation factor and fibrinogen breakdown inhibitors, such as tranexamic acid and epsilon aminocaproic acid, can be used $[21,22]$.

Other methods that can be used during surgery include ANH and autologous blood transfusion. ANH is a process of removing blood from the patient prior to surgery and maintaining intravascular volume by replacement with crystalloids and colloids [23]. Marsh and Bevan [24] reported that removed blood can be transfused when necessary, and if it is contained within a closed circuit, doing so may be acceptable to Jehovah's Witness patients. However, patients with ischemic heart disease should be excluded because physiological compensation for the acute blood loss by an accompanying increase in cardiac output is possible. For this reason, three of the 13 initial patients were ex- cluded from our study. Autologous blood transfusion methods could not be used in our surgical procedure because of the clean contaminated area.

The final aspect is postoperative patient management. After surgery, the average $\mathrm{Hb}$ level decreased from $12.0 \mathrm{~g} / \mathrm{dL}$ to $9.1 \mathrm{~g} /$ $\mathrm{dL}$ on POD 3, but recovered quickly to $10 \mathrm{~g} / \mathrm{dL}$ on POD 5. The bloodless surgery protocol we have devised alleviates the decrease in $\mathrm{Hb}$ levels caused by blood loss.

Even for orthognathic surgery, during which a significant amount of hemorrhaging is generally expected, loss of blood can be prevented through precautionary care using this approach. Also, reducing the operation time and amount of blood loss by putting together a skilled surgical team can be helpful. To avoid complications and risks related to transfusion, the methods used in our bloodless surgery center can be a novel choice for patients wishing to receive orthognathic surgery without transfusion.

\section{NOTES}

\section{Conflict of interest}

No potential conflict of interest relevant to this article was reported.

\section{Ethical approval}

The study was approved by the Institutional Review Board of Soonchunhyang University Bucheon Hospital (IRB No. 202005-042) and performed in accordance with the principles of the Declaration of Helsinki. Written informed consents were obtained.

\section{Patient consent}

The patients provided written informed consent for the publication and the use of their images.

\section{Author contribution}

Data curation: SH Lee, DG Kim. Methodology: HS Shin. Project administration: HS Shin. Writing - original draft: SH Lee, DG Kim. Writing - review \& editing: SH Lee, HS Shin.

\section{ORCID}

Sang Hwan Lee https://orcid.org/0000-0002-4923-0443

Dong Gyu Kim https://orcid.org/0000-0003-1049-4529

Ho Seong Shin https://orcid.org/0000-0002-1302-3856

\section{REFERENCES}

1. Sowade O, Warnke H, Scigalla P. Operations with a heart- 
lung machine in adult members of Jehovah's Witnesses. Anaesthesist 1995;44:257-64.

2. Suess S, Suess O, Brock M. Neurosurgical procedures in Jehovah's Witnesses: an increased risk? Neurosurgery 2001; 49:266-73.

3. Wittmann PH, Wittmann FW. Total hip replacement surgery without blood transfusion in Jehovah's Witnesses. Br J Anaesth 1992;68:306-7.

4. Li KK, Meara JG, Alexander A Jr. Location of the descending palatine artery in relation to the Le Fort I osteotomy. J Oral Maxillofac Surg 1996;54:822-7.

5. Lanigan DT, Hey JH, West RA. Major vascular complications of orthognathic surgery: hemorrhage associated with Le Fort I osteotomies. J Oral Maxillofac Surg 1990;48:56173.

6. Pineiro-Aguilar A, Somoza-Martin M, Gandara-Rey JM, et al. Blood loss in orthognathic surgery: a systematic review. J Oral Maxillofac Surg 2011;69:885-92.

7. Ueki K, Marukawa K, Shimada M, et al. The assessment of blood loss in orthognathic surgery for prognathia. J Oral Maxillofac Surg 2005;63:350-4.

8. Kretschmer W, Koster U, Dietz K, et al. Factors for intraoperative blood loss in bimaxillary osteotomies. J Oral Maxillofac Surg 2008;66:1399-403.

9. Thastum M, Andersen K, Rude K, et al. Factors influencing intraoperative blood loss in orthognathic surgery. Int J Oral Maxillofac Surg 2016;45:1070-3.

10. Choi WS, Irwin MG, Samman N. The effect of tranexamic acid on blood loss during orthognathic surgery: a randomized controlled trial. J Oral Maxillofac Surg 2009;67:125-33.

11. Olsen JJ, Skov J, Ingerslev J, et al. Prevention of bleeding in orthognathic surgery: a systematic review and meta-analysis of randomized controlled trials. J Oral Maxillofac Surg 2016;74:139-50.

12. Madsen DE, Ingerslev J, Sidelmann JJ, et al. Intraoperative blood loss during orthognathic surgery is predicted by
thromboelastography.J Oral Maxillofac Surg 2012;70:e54752.

13. Shander A, Javidroozi M. The approach to patients with bleeding disorders who do not accept blood-derived products. Semin Thromb Hemost 2013;39:182-90.

14. Scott SN, Boeve TJ, McCulloch TM, et al. The effects of epoetin alfa on transfusion requirements in head and neck cancer patients: a prospective, randomized, placebo-controlled study. Laryngoscope 2002;112(7 Pt 1):1221-9.

15. Weber RS, Jabbour N, Martin RC 2nd. Anemia and transfusions in patients undergoing surgery for cancer. Ann Surg Oncol 2008; 15:34-45.

16. Lynn S, McDaniel J. Managing severe anemia when the patient is a Jehovah's Witness. JAAPA 2013;26:24-9.

17. Lin DM, Lin ES, Tran MH. Efficacy and safety of erythropoietin and intravenous iron in perioperative blood management: a systematic review. Transfus Med Rev 2013;27:22134.

18. Bacuzzi A, Dionigi G, Piffaretti G, et al. Preoperative methods to improve erythropoiesis. Transplant Proc 2011;43: 324-6.

19. Dixon JL, Smalley MG. Jehovah's Witnesses: the surgical/ ethical challenge. JAMA 1981;246:2471-2.

20. Ball AM, Winstead PS. Recombinant human erythropoietin therapy in critically ill Jehovah's Witnesses. Pharmacotherapy 2008;28:1383-90.

21. Shaw AD, Stafford-Smith M, White WD, et al. The effect of aprotinin on outcome after coronary-artery bypass grafting. N Engl J Med 2008;358:784-93.

22. Eubanks JD. Antifibrinolytics in major orthopaedic surgery. J Am Acad Orthop Surg 2010;18:132-8.

23. Shander A. Acute normovolemic hemodilution (ANH): a practical approach. Transfus Altern Transfus Med 1999;1:710.

24. Marsh JC, Bevan DH. Haematological care of the Jehovah's Witness patient. Br J Haematol 2002;119:25-37. 